This item was submitted to Loughborough's Research Repository by the author.

Items in Figshare are protected by copyright, with all rights reserved, unless otherwise indicated.

\title{
Multi-cycle recovery of lactoferrin and lactoperoxidase from crude whey using fimbriated high-capacity magnetic cation exchangers and a novel "rotor-stator" high-gradient magnetic separator
}

\section{PLEASE CITE THE PUBLISHED VERSION}

http://dx.doi.org/10.1002/bit.24842

\section{PUBLISHER}

(c) John Wiley \& Sons, Inc.

\section{VERSION}

AM (Accepted Manuscript)

\section{LICENCE}

CC BY-NC-ND 4.0

\section{REPOSITORY RECORD}

Brown, Geoffrey N., Christine Muller, Eirini Theodosiou, Owen R.T. Thomas, and Matthias Franzreb. 2013. "Multi-cycle Recovery of Lactoferrin and Lactoperoxidase from Crude Whey Using Fimbriated High-capacity Magnetic Cation Exchangers and a Novel "rotor-stator" High-gradient Magnetic Separator". figshare. https://hdl.handle.net/2134/12017. 
Multi-cycle Recovery of Lactoferrin and Lactoperoxidase from Crude Whey using Fimbriated High-Capacity Magnetic Cation Exchangers and a Novel 'Rotor-Stator' High-Gradient Magnetic Separator

Geoffrey N. Brown, ${ }^{\mathrm{a}, 1}$ Christine Müller, ${ }^{\mathrm{a}, \mathrm{b}}$ Eirini Theodosiou, ${ }^{\mathrm{a}, 2,{ }^{*}}$ Matthias Franzreb, ${ }^{\mathrm{b}}$ and Owen R.T. Thomas ${ }^{\mathrm{a}}$

${ }^{a}$ School of Chemical Engineering, College of Engineering and Physical Sciences, University of Birmingham, Edgbaston, Birmingham, UK

${ }^{\mathrm{b}}$ Institute of Functional Interfaces, Karlsruhe Institute of Technology, EggensteinLeopoldshafen, Germany

${ }^{1}$ Current address: UCB, 638 Ajax Avenue, Slough, Berkshire, SL1 4BG

${ }^{2}$ Current address: Department of Chemical Engineering, School of Aeronautical, Automotive, Chemical and Materials Engineering, Loughborough University, Loughborough LE11 3TU, UK; telephone: 01509 222500; fax: 01509 223923; email: e.theodosiou@ lboro.ac.uk

*Correspondence to: E. Theodosiou 


\begin{abstract}
Cerium (IV) initiated 'graft-from' polymerization reactions were employed to convert MPVA magnetic particles into polyacrylic acid-fimbriated magnetic cation exchange supports displaying ultra-high binding capacity for basic target proteins. The modifications, which were performed at $25 \mathrm{mg}$ and $2.5 \mathrm{~g}$ scales, delivered maximum binding capacities $\left(Q_{\max }\right)$ for hen egg white lysozyme in excess of $320 \mathrm{mg} \mathrm{g}^{-1}$, combined with sub-micromolar dissociation constants $(0.45-0.69 \mu \mathrm{m})$ and 'tightness of binding' values greater than $49 \mathrm{~L} \mathrm{~g}^{-1}$. Two batches of polyacrylic acid-fimbriated magnetic cation exchangers were combined to form a $5 \mathrm{~g}$ pooled batch exhibiting $Q_{\max }$ values for lysozyme, lactoferrin, and lactoperoxidase of 404 , 585 and $685 \mathrm{mg} \mathrm{g}^{-1}$ respectively. These magnetic cation exchangers were subsequently employed together with a newly designed 'rotor-stator' type HGMF rig, in five sequential cycles of recovery of lactoferrin and lactoperoxidase from $2 \mathrm{~L}$ batches of a crude sweet bovine whey feedstock. Lactoferrin purification performance was observed to remain relatively constant from one HGMF cycle to the next over the 5 operating cycles, with yields between $40 \%$ and $49 \%$ combined with purification and concentration factors of $37-46$ fold and 1.3-1.6 fold respectively. The far superior multi-cycle HGMF performance seen here compared to that observed in our earlier studies can be directly attributed to the combined use of improved high capacity adsorbents and superior particle resuspension afforded by the new 'rotor-stator' HGMS design.
\end{abstract}

Keywords: adsorption; cerium (IV) initiated radical 'graft-from' polymerization; non-porous adsorbents; polyacrylic acid; polymer brushes; primary capture 


\section{Introduction}

High-Gradient Magnetic Fishing (HGMF), a robust capture technology developed in our laboratories over a decade ago, has the potential to overcome numerous barriers associated with traditional lower throughput unit adsorptive operations (Hubbuch et al., 2001; Hubbuch and Thomas, 2002; Heebøll-Nielsen et al., 2003, 2004a,b; Meyer et al., 2005, 2007; Franzreb et al., 2006, 2007). This technique combines the adsorption of the product on to cheap customized magnetic particles, with the subsequent separation of the product-loaded support from the non-magnetic components using high-gradient magnetic separation (HGMS) technology. The non-porous magnetic supports employed in HGMF have major advantages over the macro-porous adsorbents commonly used in packed and expanded bed chromatography. Apart from very rapid sorption kinetics (Heebøll-Nielsen et al., 2003; Franzreb et al., 2006, 2007), non-porous support particles are less prone to fouling and are easier to clean than their porous counterparts (O’Brien et al., 1997 and references therein) and are therefore potentially more useful in purification from fouling feed streams. Intra-particle pore fouling is an especially serious problem, as foulants lodged in pores are more difficult to remove than those adhering to the external surface. This is because internal pores within the support are not influenced by external fluid shear, so fouling material is not dislodged. By contrast, surface fouling is more readily removed by the action of fluid shear (Munro et al., 1977, Halling and Dunill, 1980).

Though to date, the number of applications of HGMS within the biotechnology sector is low, it has been employed extensively in the minerals processing industry, where it can recover micron sized magnetic particles both rapidly and efficiently, with processing rates of up to 100 tons of slurry per hour (Svoboda and Fujita, 2003). As the magnetic supports are mixed with the feedstock in a stirred tank reactor and recovered using magnetic filters typically possessing $>85 \%$ voidage, there is no need to clarify the feedstock prior to HGMF 
processing (Safarik and Safarikova, 2004). An added advantage of HGMF is the significant concentration of the target that can be achieved, which is of particular interest when the target is present in the initial feedstock at very low concentrations.

Numerous studies on the application of HGMF to recover various target molecules from diverse range of feedstocks have been reported (reviewed by Franzreb et al., 2006, 2007). From these investigations, it is clear that further work into the design of both adsorbents (higher product binding capacity, increased reusability, robustness, longevity) and magnetic filters (higher particle trapping density and more efficient support recovery) is required. Multi-cycling is the key to success in process-scale HGMF. Processing large volumes of feedstock by single cycle HGMF would require outlandishly sized magnetic filter canisters and separators, and unwarranted quantities of adsorbent (Franzreb et al., 2007). Multi-cycle operation affords the use of sensibly sized HGMF rigs. Multi-cycle HGMF is especially attractive because the quick sorption times and high fluid processing rates observed render short overall cycle times and rapid turnaround. However, certain requisites are fundamental to the future success of multi-cycle HGMF. These include automation and magnetic filter systems offering improved adsorbent holding capacities and release characteristics, and commercial provision of large quantities of cheap high capacity magnetic adsorbents able to tolerate several hundred cycles of HGMF processing per week (Franzreb et al., 2007).

In this study, we report on the practical application of two 'state-of-the-art' developments in HGMF, namely high-capacity fimbriated magnetic cation exchange supports in combination with a novel automated 'rotor-stator' HGMF system promising enhanced in situ washing and elution performance. The model system chosen for this HGMF demonstration is the recovery of lactoferrin and lactoperoxidase (LF+LPO) from crude sweet whey. 
Cerium (IV) initiated 'graft-from' polymerization reactions, initially described by Mino and Kaizerman (1958) and subsequently pioneered by Müller, Brooks and co-workers (Müller, 1986, 1990; Janzen et al., 1990; Brooks and Müller, 1996; Hritcu et al., 1999; Brooks et al., 2000) in the production of tentacular chromatography resins, were successfully applied to commercial magnetite-PVA composite particles, using procedures advanced by Brown (2009), to produce ultra-high capacity weak cation exchange adsorbents featuring dense brush-like fimbriae of polyacrylic acid (pAAc) chains. Two large batches of these pAAc-fimbriated magnetic cation exchangers were pooled, and their LPO and LF binding behavior was characterized in small scale studies with the pure proteins, before identifying the optimum $\mathrm{pH}$ for their use for 'LF+LPO' purification from crude whey. These pAAcfimbriated magnetic cation exchangers were subsequently employed in single and finally multi-cycle HGMF 'LF+LPO' recovery trials with the new 'rotor-stator' HGMF rig.

\section{Materials and Methods}

\section{Materials}

The unfunctionalized base matrix, M-PVA 012 (Lot. no. R2-0109027), used in this work is a spherical beaded 'polyvinyl alcohol (PVA) - magnetite' composite of ca. $2 \mu \mathrm{m}$ diameter, and was received as a gift from Chemagen Biopolymer-Technologie AG (Baesweiler, Germany). Brown's (2009) detailed magnetic and physical characterization of this support material revealed it to be a superparamagnetic, roughly spherical and relatively monodisperse $\left(D_{50}=\right.$ $1.9 \mu \mathrm{m}, \mathrm{D}_{20-80}$ of $\left.1.5-2.6 \mu \mathrm{m}\right)$ particle, with a high saturation magnetization $\left(42 \mathrm{Am}^{2} \mathrm{~g}^{-1}\right)$ and a highly textured surface. Unconditioned crude sweet cheese whey $(\mathrm{pH} 4.2)$ and bovine whey lactoferrin (MLF-1, 97\%) were donated by Lothar Müller Käsemanufaktur (Hockenheim, Germany) and Milei GmbH (Leutkirch, Germany) respectively, whereas lactoperoxidase from bovine milk (Calbiochem ${ }^{\circledR}$ 427489, $330 \mathrm{U} \mathrm{mg}^{-1}$ ), and chicken egg white lysozyme 
(Calbiochem ${ }^{\circledR}$ 4403), were purchased from Merck Chemicals Ltd (Nottingham, Notts, UK). All three model proteins (lactoferrin, lactoperoxidase, lysozyme) were used without further purification. The chemicals employed during M-PVA modification and subsequent binding studies - acetone ( $\geq 99.8 \%$ ), methanol ( $\geq 99.9 \%$ ), acrylic acid (anhydrous, 99\%, AAc), ammonium cerium (IV) nitrate (99.99\%), sodium sulphate (ACS reagent, anhydrous powder, $\geq 99.0 \%$ ), glacial acetic acid (ACS reagent, $\geq 99.7 \%$ ), sodium dihydrogen phosphate $(\geq 99.0 \%)$, disodium hydrogen phosphate $(\geq 99.0 \%)$, sodium chloride $(\geq 99.5 \%)$ and sodium hydroxide (pellets, anhydrous, >98\%) - were all from the Sigma-Aldrich Company Ltd (Poole, Dorset, UK), and bottled oxygen-free nitrogen gas was supplied by British Oxygen Co Ltd (Windlesham, Surrey, UK). TMB-ONE reagent was acquired from Kem-En-Tec Diagnostics (Copenhagen, Denmark), the ELISA bovine lactoferrin quantification kit was supplied by Bethyl Laboratories Inc (Montgomery, TX, USA), and the bicinchoninic acid (BCA) protein assay kit and Brilliant Blue R $(\sim 90 \%)$ were both obtained from Sigma-Aldrich. Mark12 $2^{\mathrm{TM}}$ Unstained Protein Standard, NuPAGE ${ }^{\circledR}$ LDS (Lithium dodecyl sulphate) sample buffer, NuPAGE $^{\circledR}$ MES [2-(N-morpholino) ethane sulfonic acid] SDS running buffer and 10\% NuPAGE ${ }^{\circledR}$ Bis-Tris Gels (10\% acrylamide, $1 \mathrm{~mm}$ thickness, 15 wells), were all purchased from Invitrogen (Paisley, UK). All other chemicals not stated above were from Sigma-Aldrich or Merck Chemicals Ltd.

\section{Support handling}

During all stages of functionalization and subsequent small scale testing magnetic M-PVA supports were separated from suspensions using $0.15 \mathrm{~T}$ Nd-Fe-B side-pull magnetic racks (Chemagic Stands 50k Type A and 2x12, Chemagen Bioploymer-Technologie AG, Baesweiler, Germany) or a 0.5 T Nd-Fe-B permanent magnet block (Danfysik A/S, Jyllinge, DK) for larger volumes. 


\section{Support functionalization}

A detailed description of the 'graft-from' fimbriation of non-porous M-PVA particles with polyacrylic acid (pAAc) at the $25 \mathrm{mg}$ particle scale has been reported by Brown (2009). The optimized protocol identified therein has been employed in this work, and is presented immediately below.

Prior to functionalization, M-PVA support particles $(25 \mathrm{mg})$ were washed sequentially with $5 \mathrm{~mL}$ of each of the following solutions: $50 \%$ (v/v) acetone in Milli-Q water; $100 \%$ acetone; $50 \%(\mathrm{v} / \mathrm{v})$ acetone in methanol;100 \% methanol; 50\% (v/v) methanol in Milli-Q water; twice with Milli-Q water; $1 \mathrm{M} \mathrm{NaCl}$; and finally three times with Milli-Q water. In between each wash, the particle/solution mixture was vortexed for $20 \mathrm{~s}$ using a Fisherbrand WhirliMixer $^{\mathrm{TM}}$ (Fisher Scientific UK Ltd, Loughborough, UK), before separating magnetically and removing the supernatant. The washed particles $(25 \mathrm{mg})$ were then suspended in $1.5 \mathrm{~mL}$ of degassed Milli-Q water, vortexed for $5 \mathrm{~s}$ and separated on a magnetic rack. This procedure was repeated twice, before adding $1.5 \mathrm{~mL}$ of degassed Milli-Q water and sparging the mixture with a steady stream of nitrogen for $600 \mathrm{~s}$. Acrylic acid (AAc, $88 \mathrm{mmol}$ per $g$ of support) was subsequently introduced, the tube was sealed and then placed on a Vibrax shaker $\left(\mathrm{IKA}^{\circledR}{ }^{\circledR}\right.$-Werke $\mathrm{GmbH}$, Staufen, Germany) for $300 \mathrm{~s}$ operating at $2000 \mathrm{rpm}$. A solution of ammonium cerium (IV) nitrate $(0.44 \mathrm{mmol}$ per g of support dissolved in $75 \mu \mathrm{L}$ of $2 \mathrm{M}$ nitric acid) was added under a nitrogen blanket, before re-sealing the tube, and returning to the Vibrax shaker for a further $3 \mathrm{~h}$. The supernatant was then removed with the aid of a magnetic rack and the particles were re-suspended in $3 \mathrm{~mL}$ of $0.2 \mathrm{M} \mathrm{Na}_{2} \mathrm{SO}_{3}$ in $10 \%(\mathrm{v} / \mathrm{v})$ acetic acid and vortexed for $30 \mathrm{~s}$. Finally, the pAAc-fimbriated magnetic cation exchange supports were washed: twice with Milli-Q water; twice with $1 \mathrm{M} \mathrm{NaCl}$; and again twice with Milli-Q water; before storing in $3 \mathrm{~mL}$ Milli-Q water at $4^{\circ} \mathrm{C}$ until required. 
Two much larger batches (2.5 g each) of pAAc-fimbriated magnetic cation exchangers were prepared as described in the following text. M-PVA particles $(45.7 \mathrm{~mL}$ of suspension, equivalent to 2.5 gram of dry support) were washed three times with $500 \mathrm{~mL}$ portions of Milli-Q water and then re-suspended with $150 \mathrm{~mL}$ Milli-Q water in a twin-necked $500 \mathrm{~mL}$ round bottom flask. A twin bladed glass impeller $(15 \times 7 \mathrm{~mm})$ connected to an overhead mixer (Euro Star Digital, IKA Labortechnik, Staufen, Germany) was inserted in an upright position through the large central neck of the flask, which was clamped securely to a heavy retort stand. A plastic tube fitted with a sintered glass sparger was placed through the second opening in the flask into the magnetic particle suspension, and connected to a nitrogen supply, which was turned on and set to produce a vigorous stream of bubbles. Immediately thereafter the mixer was switched on and the setting adjusted to $600 \mathrm{rpm}$. After $600 \mathrm{~s}$ of mixing under nitrogen, the nitrogen sparging tube was momentarily withdrawn to permit addition of $15 \mathrm{~mL}$ of the degassed monomer (220 mmol AAc; sparged with nitrogen) to the reaction flask, and then reintroduced. After mixing the suspension at $600 \mathrm{rpm}$ for a further $300 \mathrm{~s}$ under nitrogen, the gas sparging tube was removed once again, $7.5 \mathrm{~mL}$ of degassed initiator solution ( $0.8 \mathrm{~g}$ ammonium cerium (IV) nitrate dissolved in $10 \mathrm{~mL} 2 \mathrm{M}$ nitric acid, i.e. $1.1 \mathrm{mmol}$ ammonium cerium (IV) nitrate) was then added to start the polymerization reaction, before reintroducing it and reducing the nitrogen flow to produce a steady gentle stream of bubbles. After $3 \mathrm{~h}$ the reaction mixture was subjected to magnetic separation on a permanent magnetic plate before removing the supernatant, and washing the functionalized supports by sequential cycles of resuspension and magnetic separation using the following wash solution series: $300 \mathrm{~mL}$ of $0.2 \mathrm{M} \mathrm{Na}_{2} \mathrm{SO}_{3}$ in $10 \%$ (v/v) acetic acid; $500 \mathrm{~mL}$ of Milli-Q water (2x); 500 $\mathrm{mL}$ of $1 \mathrm{M} \mathrm{NaCl}(2 \times) ; 500 \mathrm{~mL}$ of Milli-Q water $(2 \times)$. After the last $\left(7^{\text {th }}\right)$ wash the functionalized supports from each batch were resuspended with $300 \mathrm{~mL}$ of Milli-Q water and 
stored at $4{ }^{\circ} \mathrm{C}$ until needed. The mixing time and mode employed for washing prior to and following support functionalization for the two batches made varied as follows.

$\underline{B a t c h}$ ' $A$ ': For all pre- and post- reaction washes, the supports were split evenly between two $500 \mathrm{~mL}$ Duran bottles and placed on a reciprocating shaker for $600 \mathrm{~s}$, apart from the $0.2 \mathrm{M} \mathrm{Na}_{2} \mathrm{SO}_{3}$ in $10 \%(\mathrm{v} / \mathrm{v})$ acetic acid wash, which was carried out for $60 \mathrm{~s}$.

Batch 'B': All wash steps were carried out within the twin-necked round bottom reaction vessel. The three water wash steps before the reaction and the $0.2 \mathrm{M} \mathrm{Na}_{2} \mathrm{SO}_{3}$ in $10 \%$ $(\mathrm{v} / \mathrm{v})$ acetic acid wash after the reaction were conducted for $60 \mathrm{~s}$ each, with mixing provided by the twin bladed glass impeller (rotating at $1000 \mathrm{rpm}$ ). For all other post reaction washes, mixing was achieved by vigorous manual shaking for $60 \mathrm{~s}$.

\section{Small scale protein binding studies}

Protein binding studies were carried out using three purified basic proteins, LF, LPO and lysozyme, and subsequently with crude sweet cheese whey. In small scale batch binding tests with the pure model proteins, $1 \mathrm{mg}$ portions of pAAc-fimbriated magnetic cation exchange supports were equilibrated in $20 \mathrm{mM}$ sodium phosphate buffer $\mathrm{pH} 6.8$, mixed with $1 \mathrm{~mL}$ portions of binding solution $\left(0-1 \mathrm{~g} \mathrm{~L}^{-1}\right.$ protein in phosphate buffer) and then incubated for 600 s with shaking (1250 rpm, Thermomixer Comfort shaker, Eppendorf, Hamburg, Germany). The supports were subsequently magnetically separated and the protein contents of the supernatants were analyzed (see Analysis). The protein bound to the support was determined from the difference between the protein concentration in the starting binding solution and the supernatant after binding. The resulting adsorption data for these experiments were then fitted to the Langmuir equation:

$$
Q^{*}=Q_{\max } \frac{C^{*}}{K_{d}+C^{*}}
$$


where $Q^{*}$ and $\mathrm{C}^{*}$ represent the equilibrium concentrations of adsorbed and liquid-phase protein respectively; $Q_{\max }$ is the maximum protein binding capacity of the support; and $K_{d}$ is the dissociation constant. Data was fitted to the model using the $\chi^{2}$ minimization procedure of SigmaPlot software version 10.0 (Systat Software Inc, CA, USA).

\section{Single- and multi-cycle experiments in the HGMF separator}

\section{General operation of the separator}

The new 'rotor-stator' HGMF system employed in this study (Fig. 1a; http://www.chemagen.com/cooperation-fz-karlsruhe.html) was developed at Karlsruhe's Institute of Technology (KIT; Eggenstein-Leopoldshafen, Germany) in cooperation with Chemagen Biopolymer-Technologie AG, (Baesweiler, Germany). The HGMF set-up (Figure 1b) comprised: a batch reactor for mixing the magnetic support with fresh feedstock (indicated by 'Feed' in Fig. 1b); a single two directional variable speed peristaltic pump; two computer controlled valves, which regulate the flow of process stream around the system; an air-cooled electromagnet; a specially designed 'rotor-stator' magnetic filter and associated stirrer; and a laptop computer and control software. Field strengths of up to $0.28 \mathrm{~T}$ were generated by the air-cooled magnetic solenoid coil. The 'rotor-stator' filter (internal diameter $=60 \mathrm{~mm}$; working volume $=160 \mathrm{~mL}$ ) consisted of alternating fixed and rotatable disks, spaced $3 \mathrm{~mm}$ apart (Figure 1c,d). The discs were perforated with a dense array of holes (Figure 1d), through which the solution could be pumped during operation. For particle capture, the magnetic field was switched on and whey containing suspended magnetic adsorbents was pumped through the filter. The magnetic adsorbents were strongly attracted by the narrow metallic ligaments separating the holes of the perforated discs, whilst the whey, together with all non-magnetic solids, passed through the filter unhindered. Thus, the metal ligaments of the discs play the role of matrix wires in conventional HGMS devices. Following 
separation of the magnetic adsorbents, the remaining whey in the void volume of the filter was displaced by washing buffer. The magnetic field was then switched off and the discs connected to the shaft were rotated at $1200 \mathrm{rpm}$, to enable resuspension and washing of the separated absorbents. In this way, strong shear forces were generated in the compartments between the rotating and the fixed discs, resulting in efficient particle detachment and washing. Afterwards, the particles were recaptured by switching on the magnetic field again. The described procedure for buffer displacement, resuspension and recapturing of the magnetic adsorbents was repeated with additional washing and elution steps. Finally, the adsorbents were resuspended one last time and released from the filter with the aid of the system's peristaltic pump while the magnetic field was switched off. The operation of the 'rotor-stator' HGMF rig was controlled by a software program run through Visual Basic on the connected laptop computer. Once programmed, the computer was able to control the switching of the valve positions, the speed and direction of the pump, as well as rotation of the rotor and switching the magnet 'on' and 'off' as required. Under the conditions employed the high magnetic field gradients generated by the filter in the HGMF separator result in an efficiency of particle retention very close to $100 \%$, so that no magnetic particle breakthrough was observed during any of the processing steps. According to the manufacturer, the magnetic filter capacity is sufficient to handle $>20 \mathrm{~g}$ of magnetic M-PVA support, i.e. $>4$ fold higher than the amount employed in this work (ca. $5 \mathrm{~g})$. In other studies, employing the same 'rotorstator' filter and $20 \mathrm{~g}$ of M-PVA particles, particle loss was estimated at just $0.1 \%$ per full operating cycle. In each cycle the adsorbent particles were magnetically separated 8 times; translating to an average separation efficiency per step of $>99.98 \%$.

\section{Single-cycle HGMF operation}


Following equilibration in $20 \mathrm{mM}$ sodium phosphate buffer, $\mathrm{pH} 7.5,5 \mathrm{~g}$ of pAAc-fimbriated magnetic cation exchange matrix was transferred to a $4 \mathrm{~L}$ batch reactor and mixed with $2 \mathrm{~L}$ of sweet cheese whey (pretreated by filtration through a $100 \mu \mathrm{m}$ filter and $\mathrm{pH}$ adjustment to 7.5 with $3.5 \%$ w/v NaOH) at $350 \mathrm{rpm}$ by an overhead mixer fitted with a steel twin-bladed impeller $(40 \times 12 \mathrm{~mm})$. After mixing for $600 \mathrm{~s}$, the rotation speed was reduced to $150 \mathrm{rpm}$ and the 'magnetic adsorbents/feedstock' suspension was applied to the filter at a flow rate of $8.0 \mathrm{~L}$ $\mathrm{h}^{-1}$ with the magnetic field turned 'on'. The target-laden adsorbent particles were captured in the magnetized filter, whereas the target depleted feedstock passed through, and was collected as the 'flow through' fraction. With the field still 'on', $450 \mathrm{~mL}$ of $20 \mathrm{mM}$ sodium phosphate buffer, pH 7.5 was then pumped through the filter at $6.6 \mathrm{~L} \mathrm{~h}^{-1}$ ) for $240 \mathrm{~s}$ to flush out any residual feedstock and fill the filter and lines with wash buffer. The output from the rig was collected and labelled 'Wash 1'. The recycle loop was then closed, the pump stopped and the particles were resuspended in wash buffer by turning on the stirrer for $60 \mathrm{~s}$ at 'zero' magnetic field. Particle collection was initiated by switching the stirrer off and the magnetic field back on for $30 \mathrm{~s}$ without pumping the process stream around the recycle loop, before continuing collection with the pump at $6.6 \mathrm{~L} \mathrm{~h}^{-1}$ for $120 \mathrm{~s}$. This wash procedure was repeated twice more, and fractions 'Wash 2' and 'Wash 3' were collected. The filter and lines were then filled with $110 \mathrm{~mL}$ of elution buffer $(20 \mathrm{mM}$ sodium phosphate buffer, $\mathrm{pH} 7.5$ supplemented with $1 \mathrm{M}$ $\mathrm{NaCl}$ ) by pumping the buffer through the filter at $6.6 \mathrm{~L} \mathrm{~h}^{-1}$ for $60 \mathrm{~s}$, and simultaneously flushing out remaining wash buffer, which was collected as 'Wash 4'. The particles were then resuspended in the elution buffer by turning off the magnet and switching on the stirrer for a prolonged time of $300 \mathrm{~s}$, before recollecting the particles as described above. Elution buffer was then pumped though the filter once more; this time for $110 \mathrm{~s}$ at $6.6 \mathrm{~L} \mathrm{~h}^{-1}$ whilst 'Elution 1' was collected $(200 \mathrm{~mL})$. The support was resuspended and collected as done previously. The third filling with elution buffer was carried out in the same way as the second, whilst 
collecting the fraction 'Elution 2'. Once elution was complete, the particles were washed to prepare them for the next sorption step by pumping $300 \mathrm{~mL}$ of wash buffer through the filter three more times, each time following the same wash procedure of particle resuspension and recollection as carried out before elution (described above), collecting 'Elution 3', 'Wash 5' and 'Wash 6' respectively. Once the particles had been resuspended after filling with wash buffer for the $6^{\text {th }}$ time, instead of turning on the magnetic field and collecting the particles in the filter (as had been done each previous time), the particles were rapidly flushed out of the system with $2 \mathrm{~L}$ of wash buffer by pumping at $11.5 \mathrm{~L} \mathrm{~h}^{-1}$ with the magnetic field 'off' and the stirrer switched 'on' to aid support resuspension. The used support was flushed into a Duran bottle, where it was concentrated by magnetic settling on a permanent magnet block (Danfysik A/S, Jyllinge, DK) followed by removal of $1.5 \mathrm{~L}$ of the supernatant, before storing at $4^{\circ} \mathrm{C}$.

\section{Multi-cycle HGMF operation}

When operating the rig in multi-cycle mode, subsequent process cycles were started by flushing the washed support at the end of the previous cycle from the filter directly into the batch reactor using the next $2 \mathrm{~L}$ of whey to be processed. Once all of the whey had been flushed through the system, batch adsorption of the target species onto the magnetic cation exchange adsorbent particles was carried out for $600 \mathrm{~s}$, before pumping the feedstock suspension through the filter and following the single-cycle operation process as described previously. At the end of the final cycle, the adsorbent particles were flushed from the filter using wash buffer, and following magnetically-aided settling were stored at $4{ }^{\circ} \mathrm{C}$ in $20 \%(\mathrm{v} / \mathrm{v})$ ethanol. Each complete cycle (mixing support with whey, loading into the filter, washing, eluting and rinsing support back out of filter) took approximately $2 \mathrm{~h}$. 


\section{Analytical techniques}

Magnetic particle concentrations were determined by a dry weight method based on that described by Hubbuch and Thomas (2002). Sterile $0.45 \mu \mathrm{m}$ filters (Gelman Sciences, Ann Arbor, MI, USA) were placed in a $60^{\circ} \mathrm{C}$ oven overnight, then cooled to room temperature in a dessicator jar and weighed on an analytical balance. Samples $(200 \mu \mathrm{L})$ containing magnetic particles were applied to these filters, and then filtered under vacuum before drying to constant weight. After cooling to room temperature in a dessicator jar, the filters were reweighed and the amount of support particles in each sample was calculated from the change in weight of the filter. In small scale binding experiments using single proteins, the protein contents of bulk liquid phase samples was determined by measurement of the absorbance at $280 \mathrm{~nm}$ in quartz cuvettes in an Agilent 8453 Spectrophotometer (Agilent Technologies, Santa Clara, CA, USA). In studies employing whey, soluble protein contents were determined by the BCA assay adapted for use with the Cobas Mira spectrophotometric robot. The concentration of LF in solutions containing other proteins was measured using an ELISA bovine lactoferrin quantification kit following the manufacturer's instructions, whereas LPO activity was measured using TMB-ONE ready-to-use substrate $\left(3,3^{\prime}, 5,5^{\prime}\right.$ - tetramethyl benzidine) according to the manufacturer's instructions, and was scaled for automation in a Cobas Mira Plus spectrophotometric robot (Roche Diagnostics, Switzerland) as described previously (Heebøll-Nielsen et al., 2004a). LPO activity was followed by monitoring the change in absorbance at $600 \mathrm{~nm}$ due to formation of the deep blue product, 3,3',5,5'tetramethyl benzidine. Product formation was followed at $37^{\circ} \mathrm{C}$ by measuring the change in absorbance at $600 \mathrm{~nm}$ after mixing 3 volumes of sample with 37 volumes of the reagent.

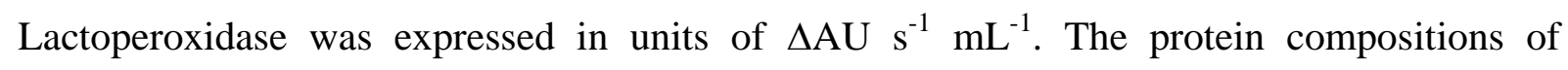
fractions generated in magnetic cation exchange separation experiments with whey feedstocks were analyzed by reducing SDS-PAGE (Laemmli, 1970) in 10\% (w/v) polyacrylamide gels. 
All sample preparation and electrophoresis operations were conducted using NuPAGE ${ }^{\circledR}$ reagents and materials (Invitrogen, Paisley, UK). Samples for electrophoresis were mixed with $5 \mu \mathrm{L}$ of $4 \mathrm{x}$ NuPAGE ${ }^{\circledR}$ LDS sample loading buffer and the total volumes of each were adjusted to $20 \mu \mathrm{L}$, before mixing at $70^{\circ} \mathrm{C}$ and $1400 \mathrm{rpm}$ in a pre-heated Thermomixer Comfort shaker for $600 \mathrm{~s}$. After cooling on ice, $10 \mu \mathrm{L}$ volumes were loaded onto $10 \%$ NuPAGE ${ }^{\circledR}$ Bis-Tris Gels and were electrophoresed in XCell SureLock ${ }^{\mathrm{TM}}$ Mini-Cell systems (Invitrogen) at $200 \mathrm{~V}$ for $0.6 \mathrm{~h}$ with $\mathrm{NuPAGE}^{\circledR} \mathrm{MES}$ SDS pH 7.3, as the running buffer. After electrophoresis gels were stained with $0.1 \%(\mathrm{w} / \mathrm{v})$ Brilliant Blue R, dissolved in $40 \%(\mathrm{v} / \mathrm{v})$ ethanol and $10 \%(\mathrm{v} / \mathrm{v})$ acetic acid) for $1 \mathrm{~h}$ at room temperature, and were subsequently destained at the same temperature in a solution composed of $7.5 \%(\mathrm{v} / \mathrm{v})$ acetic acid and $10 \%$ (v/v) ethanol. Images of appropriately loaded gels were captured with an HP ScanJet C7716A flat bed scanner (Hewlett Packard UK, Bracknell, Berks, UK) at a resolution of 2400 dpi. The relative densities of protein bands on destained gels were analyzed using ImageJ software, downloaded from http://rsb.info.nih.gov/ij/.

\section{Results and Discussion}

\section{Lysozyme binding characteristics of pAAc - fimbriated magnetic cation exchanger supports}

Figure 2a shows lysozyme adsorption isotherms obtained with the pAAc-fimbriated M-PVA supports prepared in this work, and Table I summarizes the Langmuir parameters fitted to the data sets. Though high maximum lysozyme binding capacities and sub-micromolar $K_{d}$ values were noted in all cases, it was clear that significant loss in sorption performance had occurred on scaling up the fimbriation reactions 100-fold. For example, the first $2.5 \mathrm{~g}$ batch prepared (Batch A) possessed a lysozyme sorption capacity less than half that of the $25 \mathrm{mg}$ batch (319 $c f .660 \mathrm{mg} \mathrm{g}^{-1}$; Table I), but despite this retained a similarly impressive $K_{d}(0.45 c f .0 .52 \mu \mathrm{M}$; 
Table I). No noticeable differences in appearance or handling characteristics of the 25 and 2.5 $\mathrm{g}$ batches of finished magnetic cation exchangers were noted (all three preparations were completely separated from solution within $60 \mathrm{~s}$ when placed in a magnetic rack). Possible causes for the lower lysozyme sorption performance of the $2.5 \mathrm{~g}$ 'batch A' and reasons for subsequently revising the protocols for producing a subsequent $2.5 \mathrm{~g}$ lot (batch B) are offered immediately below.

In a crude attempt to mimic the vortex-mediated washing operations applied pre- and post- graft polymerization at the $25 \mathrm{mg}$ scale during preparation of 'batch A' pAAcfimbriated magnetic cation exchangers the support was split between two $500 \mathrm{~mL}$ Duran bottles. Half of the various wash buffers were added to each bottle, and the suspensions were vigorously agitated by shaking on a reciprocating shaker, for $600 \mathrm{~s}$ per wash. However, the large head space created in each bottle (50\% of the total volume) led to excessive foaming and generation of a stable foam composed of tiny air bubbles and fine magnetic particles. With this observation in mind the physical entrapment between and/or adherence of microscopic air bubbles to M-PVA particles was considered highly plausible. Should removal of air micro-bubbles from the surfaces of M-PVA be incomplete during nitrogen sparging of the support suspension prior to addition of the polymerization initiator, then trace levels of oxygen would be present in the reaction mixture. It is well known that oxygen 'poisons' free radical based polymerization reactions (Müller, 1986); thus failure to ensure complete removal of entrained air micro-bubbles from the support is likely to seriously compromise the efficiency of 'graft-from' polymerization of pAAc into the surfaces of M-PVA.

In light of the above, a second large scale functionalization reaction was subsequently performed (yielding batch B) in which washing was carried out in the twin-necked round bottom flask used for the reaction. Each washing step was carried out in situ for $60 \mathrm{~s}$ with mixing provided by the impeller rotating at $1000 \mathrm{rpm}$. The resulting $Q_{\max }$ of $519 \mathrm{mg}$ lysozyme 
$\mathrm{g}^{-1}$ marked a considerable improvement over that of 'batch A', and was deemed sufficiently close to that of the analogous small-scale preparation (see Table I; $Q_{\max }=660 \mathrm{mg} \mathrm{g}^{-1}$ ) to merit no need for further method optimization work prior to commencing studies with unclarified whey and HGMF. This said, the need for systematic investigations into the factors affecting scale-up of 'graft-from' polymerization reactions applied to non-porous magnetic supports is clearly imperative. Controlling the mixing conditions applied during washing and polymerization reaction steps is especially important in this context. The use of improved gastight multi-port reaction vessels, fitted with devices delivering efficient and 'air micro-bubble free' mixing will undoubtedly help.

\section{LF and LPO binding behavior of pooled $5 \mathrm{~g}$ batch of pAAc - fimbriated magnetic cation exchangers}

The two $2.5 \mathrm{~g}$ batches of pAAc-grafted M-PVA were combined to give a $5 \mathrm{~g}$ pooled batch of magnetic cation exchangers, which was employed in all subsequent experiments. The pooled batch, which was characterized by an estimated $Q_{\max }$ for lysozyme of $404 \mathrm{mg} \mathrm{g}^{-1}$ (Figure $2 \mathrm{~b}$, Table II) bound pure LF and LPO at even higher capacities ( $Q_{\max }$ values of 586 and $685 \mathrm{mg} \mathrm{g}^{-}$ ${ }^{1}$ for LF and LPO respectively), albeit much less strongly as judged from the magnitude of the initial slopes (Table II). The binding properties of these new fimbriated magnetic cation exchangers deserve comparison with the best magnetic cation exchange material previously constructed in our laboratories. In a comprehensive study Heebøll-Nielsen and coworkers (2004a) fabricated 8 different types of magnetic cation exchangers based on the $0.6 \mu \mathrm{m}$ polyglutaraldehyde-coated superparamagnetic particle, and found that the best binding properties were exhibited by a preparation route employing multiple rounds of epichlorohydrin activation followed by sulfite coupling. The authors speculated that the superior performance of these essentially non-porous magnetic cation exchange adsorbents 
was due to in situ formation of oligomeric sulfite functionalized tentacles at the support surface. Heebøll-Nielsen and colleagues (2004a) reported $Q_{\max }, K_{d}$ and initial slope values for the binding of lysozyme to this material of $272 \mathrm{mg} \mathrm{g}^{-1}, 0.73 \mu \mathrm{M}$ and $26.2 \mathrm{~L} \mathrm{~g}^{-1}$ respectively. Exactly the same adsorbent design was employed in later work by Meyer et al. (2007) who reported a maximum capacity for LF in purified form of $335 \mathrm{mg} \mathrm{g}^{-1}$. It is clear that the act of growing polyacrylic acid fimbriae out from the $2 \mu \mathrm{m}$ sized M-PVA magnetic base particles results in a significantly improved magnetic cation exchange material.

\section{Single-cycle HGMF processing of whey}

The results of LF and LPO recovery in the first cycle of HGMF are respectively summarized in Tables III and IV, and Figure 3a shows the corresponding SDS-PAGE analysis of selected fractions from the run. For the HGMF process, a particle concentration of $2.5 \mathrm{~g} \mathrm{~L}^{-1}$ was selected. Using 5 grams of functionalized support at this concentration, it was possible to process $2 \mathrm{~L}$ of whey per cycle, i.e. representing a 2000-fold volume increase $c f$. laboratory scale experiments. Following the batch adsorption step, which was performed in a stirred vessel, $~ 56 \%$ of the LF (Table III) and nearly $62 \%$ of the LPO (Table IV) initially present had been removed from the whey. Physically entrained and non-specifically adsorbed soluble and insoluble matter was removed in four sequential washing steps after which the amounts of LF and LPO still adsorbed fell to $49.3 \%$ and $58.5 \%$ respectively. From Figure $3 \mathrm{a}$ it is clear that the wash stringency before elution could have been higher, as the $4^{\text {th }}$ wash (lane 10) still contains significant amounts of impurities (Ig, BSA, $\beta-\mathrm{LG}, \alpha-\mathrm{LA})$. Bound LF and LPO were recovered from the magnetic cation exchange adsorbents in three elution cycles. Both species were recovered from the supports in high yield (88\% for LF and $132 \%$ for LPO when expressed as percentages of that initially adsorbed) and in substantially purified forms (Figure 3a), i.e. $>44$ fold for LF (Table III) and $>73$ fold for LPO (Table IV). The mass balances for 
LF and protein closed to 99.7 and $106.2 \%$ respectively. For LPO the elevated mass balance of $123 \%$ provides evidence that enzyme activation had taken place during the purification process. In their work on the use of magnetic cation exchangers for LPO recovery from whey by HGMF Heebøll-Nielsen and co-workers (2004a) came to the same conclusion (reporting protein and LPO mass balances of $96.3 \%$ and $119 \%$ respectively). The HGMF purification performance delivered by the new fimbriated magnetic cation exchangers employed in this work for the recovery of basic proteins from whey represents a significant improvement over the best previous magnetic cation exchanger (i.e. the oligomeric sulfite linked material) identified by Heebøll-Nielsen et al. (2004a). These researchers reported a final purification factor for recovery of LPO from whey by HGMF of 36.4, and in later work using the same type of magnetic support for the recovery of LF from whey, Meyer et al. (2007) reported that LF was purified 18.6-fold.

The overall concentration factors of 1.4 and 2.3 for LF and LPO respectively are lower than those reported previously (Heebøll-Nielsen et al., 2004a; Meyer et al., 2007). This was not unexpected as the concentration factor achieved depends heavily on the support holding capacity of the magnetic filter. In this work less than one quarter $(5 \mathrm{~g})$ of the maximum magnetic particle holding capacity of the magnetic filter (>20 g) was utilized. Much higher concentration factors (estimated to be $\sim 5.6$ and $\sim 9.2$ fold for LF and LPO respectively) could therefore be easily achieved simply by filling the magnetic filter to its maximum particle holding capacity.

\section{Multi-cycle HGMF processing of whey}

In order to minimize whey degradation effects (Fuda and Jauregi, 2006) subsequent cycles of HGMF, employing the same batch of support, were carried out within $40 \mathrm{~h}$ of the single-cycle HGMF run. The magnetic cation exchangers were flushed out of the magnetic filter at the end 
of the single cycle HGMF experiment using $1 \mathrm{~L}$ of equilibration buffer and stored at $4^{\circ} \mathrm{C}$ until required for multi-cycle HGMF. At the start of the experiment the support was loaded onto the magnetic filter and then rinsed out of it at 'zero field' using the first of the four batches of whey that were to be processed. Given that no extra regeneration or CIP steps were carried out between the single- and multi-cycle runs, it can be assumed that the same batch of particles was used in five consecutive cycles of HGMF (i.e. the single cycle HGMF run represents the $1^{\text {st }}$ cycle in the 5-cycle series of HGMF).

Tables V and VI respectively summarize the LF and LPO purification data obtained in the multi-cycle HGMF experiments. Meyer et al. (2007) reported drops in LF yield and purification factor over three successive process cycles, citing difficulties with recovery of the magnetic support from the filter as a major cause of this. In other work on multi-cycle HGMF processing of whey employing Heebøll-Nielsen and coworkers' (2004a) oligomeric sulfite functionalized polyglutaraldehyde-coated magnetic support design, Gomes (2006) also reported poor consistency in purification performance during multi-cycle HGMF, and attributed this to inefficient release and resuspension of the adsorbent from the magnetic filter recycle loop during binding and elution operations. In subsequent tests (Gomes, 2006; Ebner et al., 2007) using a large number of new filter designs with defined wire orientations it became clear that the nature of the base support very strongly influenced both the achievable particle loading capacity; and ease of particle release from the filters. For example, the working particle holding capacities of the different filters were typically 3-4 fold lower for the polyglutaraldehyde-coated $c f$. M-PVA support (Ebner et al., 2007), and the flushing efficiencies were also much poorer for this material, i.e. typically 2-3 times lower than for MPVA (Gomes, 2006).

In one of the earliest HGMF studies, Hubbuch and Thomas (2002) noted that the recovery of magnetic adsorbents from filters following magnetic capture represented a 
significant obstacle in HGMF processing. In their work they employed polyglutaraldehydecoated magnetic supports, and in all subsequent studies employing this base material, except one, i.e. Heebøll-Nielsen and co-workers' (2004b) work on the purification of the lectin, Concanavalin A from crude Jack bean extract, similar difficulties have been reported. This study differed from others in that the polyglutaraldehyde-coated magnetic particles were heavily surface-grafted (10\% by weight) with long dextran chains, and complete particle recovery from the magnetic filter was achieved simply by flushing at a high flow rate without need of mechanical assistance. The authors suggested that the excellent flushing characteristics observed might be attributed to the end-grafted carbohydrate tentacle layer functioning in a way that might prevent 'too close' particle approach, making for weaker inter-particle aggregation within the filter, so facilitating particle release from it at zero field. Inefficient support recovery from the magnetic filter does not appear to be a major problem in this work. The purification factors $(43.6 \pm 3.9)$, target yields $(44.2 \pm 3.8 \%)$ and concentration factors $(1.42 \pm 0.11)$ observed for LF remained relatively constant over the five HGMF cycles (Table V) and visual confirmation of this was revealed by SDS-PAGE analysis of eluate fractions derived from four of the five sequential runs (Figure 3b). Unlike all previous HGMF systems studied to date, resuspension of the support from the 'rotor-stator' filter system employed in this work is achieved by rapidly rotating the alternate disks which make up the filter (Figure 1c,d). During their rotation, shear forces are generated in the liquid between the disks which aids re-suspension of the captured supports. The results from this multi-use study indicate that this method of resuspension is a considerable improvement on previous magnetic filter designs. It should be noted that high shear stresses developed in the 'rotor-stator' do not appear to inflict damage on the magnetic support particles used in this work. Support for this comes from the observation, in this study, of unaltered performance over the 5 operation cycles, and also from other investigations with the same separator unit, employing almost 
twice the magnetic particle loading ( $9 \mathrm{~g}$ ) over $>10$ successive runs, where we have been unable to detect any evidence of particle degradation. The apparent robustness of the support particles is likely attributable, at least in part, to their very small size, given that for any particle type, susceptibility to attrition is inversely proportional to particle size (Bond, 1952; Ahuja, 1976; Baláž, 2008).

In contrast to the relatively constant LF purification performance across five sequential HGMF cycles, the recovery and purity of the more weakly adsorbing LPO was seen to diminish rather dramatically with each new HGMF run. No evidence for LPO inactivation within the whey feedstock was observed over the $48 \mathrm{~h}$ period within which all five HGMF runs were conducted (measured LPO activities in the whey were 90, 103, 102, 105 and $111 \mathrm{U} \mathrm{mL}^{-1}$ respectively, for the five consecutive HGMF runs). LPO is present at much lower concentrations within whey than LF, and furthermore its binding to cation exchangers is much more acutely sensitive to the presence of low concentrations of $\mathrm{NaCl}$. For example, Recio and Visser (1999) observed that as little as $50 \mathrm{mM} \mathrm{NaCl}$ seriously impaired LPO adsorption on cation exchangers, whereas LF binding was unaffected. The elution buffer employed in this work contained $1 \mathrm{M} \mathrm{NaCl}$. In these experiments specific cleaning and reequilibration steps were not employed between cycles, and thus it is highly plausible that some 'carry-over' of elution buffer into the adsorption step of the next HGMF cycle could have occurred. Note, just a 5\% 'carry-over' of the elution buffer into the whey feedstock would be equivalent to adding $50 \mathrm{mM} \mathrm{NaCl}$.

\section{Conclusions}

A prominent feature of this work is the combination of 'state-of-the-art' magnetic cation exchange supports with a 'state-of-the-art' automated HGMF rig designed to enhance in situ adsorbent washing and elution performance. Cerium (IV) initiated 'graft-from' 
polymerization reactions, previously optimized at small scale (25 mg) by Brown (2009) to produce high-capacity magnetic cation exchangers with polyacrylic acid fimbriae, were scaled 100-fold to provide sufficient magnetic cation exchange material for demonstration of HGMF. Binding studies conducted at small scale with pure hen egg white lysozyme revealed that significant reduction in maximum adsorption capacity had occurred on scale up, highlighting an imperative future need, i.e. systematic study and optimization of the scale up of polymer grafting reactions (and associated purging, mixing, washing operations) applied to fine magnetic particle supports. Nevertheless, the sorption performance of a pooled $5 \mathrm{~g}$ batch (A+B) was still high (i.e. $Q_{\max }, K_{d}$ and initial slopes of $404,0.51 \mu \mathrm{M}$ and $55 \mathrm{~L} \mathrm{~g}^{-1}$ respectively cf. corresponding values of $660 \mathrm{mg} \mathrm{g}^{-1}, 0.52 \mu \mathrm{M}$ and $88 \mathrm{~L} \mathrm{~g}^{-1}$ for the $25 \mathrm{mg}$ batch) and encouraged direct progression to HGMF whey processing trials using the automated 'rotorstator' separator.

Five consecutive cycles of HGMF were employed for the recovery of the basic nutriceutical proteins, LF and LPO, from 2 L batches of a crude bovine sweet whey feedstock. Over the five cycles all key aspects of LF purification performance (yield, purification and concentration factors) remained constant, a feat not previously achieved in multi-cycle HGMF. The same could not, however, be claimed for LPO where the dramatic drops in yield, purification and concentration factor observed are believed to be due to insufficient washing of the particles between each batch, resulting in 'carry-over' of trace amounts of $\mathrm{NaCl}$, which is known to severely undermine the binding characteristics of LPO to cation exchangers. By using substantially higher magnetic support concentrations during the binding step, and by increasing the amount of particles applied close to the filter's maximum ca. 5-fold (i.e. approaching the filters' particle holding capacity), it should be possible to significantly improve both the yield and the concentration of LF. Optimizing multi-cycle LPO recovery would require systematic investigation of the effects of $\mathrm{NaCl}$ on binding, and evaluation of 
various washing regimes, so as to minimize negative 'carry-over' impacts from one cycle on subsequent LPO sorption performance in the next.

Small commercial solenoid magnets featuring open bores of $40 \mathrm{~cm}$ diameter and 30 $\mathrm{cm}$ in length are widely employed in minerals processing (Svoboda, 2004). The separator volume of a 'rotor-stator' HGMS system of these dimensions would be $c a .32$ L. Assuming the same cycle times, magnetic adsorbent particles and volumetric capacities (i.e. LF captured per L of separator volume) identified in this work can be applied to a single $32 \mathrm{~L}$ 'rotor-stator' HGMS device, such a system could handle a respectable $6.4 \mathrm{~m}^{3} /$ day; a throughput sufficient for many bioprocesses. For whey processing however, given the huge quantities of whey produced worldwide (Koutinas et al., 2007) very much larger commercial solenoid magnets with $3 \mathrm{~m}$ diameter bores (Svoboda, 2004) capable of handling an estimated $640 \mathrm{~m}^{3} /$ day, would be more appropriate.

Further work on multi-cycle HGMF using high-capacity magnetic adsorbents and 'rotor-stator' magnetic separators merits urgent investigation. There is a pressing need to extend such studies to a wide range of test systems and adsorbent chemistries, and perhaps more important, to conduct greater numbers of cycles.

\section{Acknowledgements}

This work was supported by a European Commission Framework VI Strategic Targeted Research Project (No. 013469 'Magnetic field assisted Biomaterials Processing, 'NANOBIOMAG'), and a PhD studentship awarded to GNB by the UK's Biotechnology and Biological Sciences Research Council. We also thank Jörg Becker for technical assistance with the ProMagic 'rotor-stator' high-gradient magnetic separator rig. 


\section{References}

Ahuja SK. 1976. A degradation mechanism during flow of polymer-coated metal spheres, J. Colloid Interface Sci 57: 438-445.

Baláž P. 2008. Mechanochemistry in nanoscience and minerals engineering. Springer-Verlag Berlin Heidelberg.

Bond, FC, 1952. The third theory of comminution. Trans Am Inst Min Eng 193: 484-494.

Brooks DE, Müller W. 1996. Size-exclusion phases and repulsive protein-polymer interaction/recognition. J Mol Recognit 9: 697-700.

Brooks DE, Haynes CA, Hritcu D, Steels BM, Müller W. 2000. Size-exclusion chromatography does not require pores. Proc Natl Acad Sci USA 97: 7064-7067.

Brown GN. 2009. Advances in magnetic particle based bioprocesses. PhD Thesis. Birmingham: The University of Birmingham.

Ebner N, Gomes CSG, Hobley TJ, Thomas ORT, Franzreb M. 2007. Filter capacity predictions for the capture of superparamagnetic microparticles by high-gradient magnetic separation (HGMS). IEEE Trans Magn 43(5):1941-1949.

Franzreb M, Ebner N, Siemann-Herzberg M, Hobley TJ, Thomas ORT. 2007. Product recovery by High-Gradient Magnetic Fishing. In: Shukla AA, Etzel M, Gadam S, editors. Process scale bioseparations for the biopharmaceutical industry. CRC Press. p $83-122$.

Franzreb M, Siemann-Herzberg M, Hobley TJ, Thomas ORT. 2006. Protein purification using magnetic adsorbent particles. Appl Microbiol Biotechnol 70(5):505-516.

Fuda E, Jauregi P. 2006. An insight into the mechanism of protein separation by colloidal gas aphrons (CGA) generated from ionic surfactants. J Chromatogr B 843(2):317-326.

Gomes CSG. 2006. Advances in High-Gradient Magnetic Fishing for Bioprocessing. PhD Thesis. Lyngby: Technical University of Denmark. 
Hahn R, Schulz PM, Schaupp C, Jungbauer A. 1998. Bovine whey fractionation based on cation-exchange chromatography. J Chromatogr A 795(2):277-287.

Halling PJ, Dunnill P. 1980. Magnetic supports for immobilised enzymes and bio-affinity adsorbents. Enzyme Microb Technol 2: 3-10.

Heebøll-Nielsen A, Choe WS, Middelberg APJ, Thomas ORT. 2003. Efficient inclusion body processing using chemical extraction and high gradient magnetic fishing. Biotechnol Progr 19(3):887-898.

Heebøll-Nielsen A, Justesen SFL, Hobley TJ, Thomas ORT. 2004a. Superparamagnetic cation-exchange adsorbents for bioproduct recovery from crude process liquors by highgradient magnetic fishing. Sep Sci Technol 39(12):2891-2914.

Heebøll-Nielsen A, Dalkiaer M, Hubbuch JJ, Thomas ORT. 2004b. Superparamagnetic adsorbents for high-gradient magnetic fishing of lectins out of legume extracts. Biotechnol Bioeng 87(3):311-323.

Hritcu D, Müller W, Brooks DE. 1999. Poly(styrene) latex carrying cerium(IV)-initiated terminally attached cleavable chains: Analysis of grafted chains and model of the surface layer. Macromolecules 32: 565-573.

Hubbuch JJ, Thomas ORT. 2002. High-gradient magnetic affinity separation of trypsin from porcine pancreatin. Biotechnol Bioeng 79(3):301-313.

Janzen R, Unger KK, Müller W, Hearn, MTW. 1990. Adsorption of proteins on porous and nonporous poly(ethyleneimine) and tentacle-type anion-exchangers. J. Chromatogr. 522: 77-93.

Koutinas AA, Athanasiadis I, Bekatorou A, Psarianos C, Kanellaki M, Agouridis N, Blekas G. 2007. Kefir-yeast technology: Industrial scale-up of alcoholic fermentation of whey, promoted by raisin extracts, using kefir-yeast granular biomass. Enzyme Microb Technol 41(5):576-582. 
Meyer A, Berensmeier S, Franzreb M. 2007. Direct capture of lactoferrin from whey using magnetic micro-ion exchangers in combination with high-gradient magnetic separation. React Funct Polym 67(12):1577-1588.

Mino G. Kaizerman S. 1958. A new method for the preparation of graft copolymers. polymerization initiated by ceric ion redox system. J Polym Sci 31(122): 242-243.

Müller W. 1986. New phase supports for liquid-liquid partition chromatography of biopolymers in aqueous poly(ethyleneglycol)-dextran systems - synthesis and application for the fractionation of DNA restriction fragments. Eur J Biochem 155(1):213-222.

Müller W. 1990. New ion exchangers for the chromatography of biopolymers. J Chromatogr A 510: 133-140.

Munro PA, Dunnill P, Lilly, MD. 1977. Non-porous magnetic materials as enzyme supports: Studies with immobilised chymotrypsin. Biotechnol Bioeng 19: 101-124.

O'Brien SM, Sloane RP, Thomas ORT, Dunnill P. 1997. Characterisation of non-porous magnetic chelator supports and their use to recover polyhistidine-tailed T4 lysozyme from a crude E. coli extract. J Biotechnol 54:53-67.

Recio I, Visser S. 1999. Two ion-exchange chromatographic methods for the isolation of antibacterial peptides from lactoferrin - In situ enzymatic hydrolysis on an ion-exchange membrane. J Chromatogr A 831(2):191-201.

Safarik I, Safarikova M. 2004. Magnetic techniques for the isolation and purification of proteins and peptides. Biomagn Res Technol 2(1):7-24.

Svoboda J, Fujita T. 2003. Recent developments in magnetic methods of material separation. Miner Eng 16(9):785-792.

Svoboda J. 2004. Magnetic Techniques for the Treatment of Materials. Kluwer Academic Publishers, Dordrecht, Netherlands. 
Table I. Langmuir parameters ${ }^{\mathrm{a}}$ describing the adsorption of lysozyme to pAAc-fimbriated magnetic cation exchangers functionalized at ' $25 \mathrm{mg}$ ' and ' $2.5 \mathrm{~g}$ ' scales.

\begin{tabular}{llll}
\hline $\begin{array}{l}\text { M-PVA particles used } \\
(\mathbf{m g})\end{array}$ & $\boldsymbol{Q}_{\max }\left(\mathbf{m g ~ g}^{-\mathbf{1}}\right)$ & $\boldsymbol{K}_{\boldsymbol{d}}(\boldsymbol{\mu M})$ & $\begin{array}{l}\text { Initial slope, } \\
\mathbf{Q}_{\max } / \boldsymbol{K}_{\boldsymbol{d}}\left(\mathbf{L} \mathbf{~ g}^{-\mathbf{1}}\right)\end{array}$ \\
\hline 25 & $660.2 \pm 45.4$ & $0.52 \pm 0.13$ & 88.0 \\
2500 (batch A) & $318.7 \pm 9.6$ & $0.45 \pm 0.08$ & 49.0 \\
2500 (batch B) & $519.2 \pm 23.3$ & $0.69 \pm 0.14$ & 52.4
\end{tabular}

${ }^{\mathrm{a}}$ Figure 2a adsorption isotherm data were fitted to the Langmuir model (Eqn 1). 
Table II. Langmuir parameters ${ }^{\mathrm{a}}$ describing the adsorption of LF, LPO and lysozyme to the pooled $5 \mathrm{~g}$ batch (batch $\mathrm{A}+$ batch $\mathrm{B}$ ) of $\mathrm{pAAc}-$ fimbriated magnetic cation exchangers.

\begin{tabular}{lllc}
\hline Sample & $\begin{array}{l}\boldsymbol{Q}_{\max } \\
\left(\mathbf{m g ~ g}^{-\mathbf{1}}\right)\end{array}$ & $\begin{array}{l}\boldsymbol{K}_{\boldsymbol{d}} \\
(\boldsymbol{\mu M})\end{array}$ & $\begin{array}{l}\text { Initial slope, } \\
\boldsymbol{Q}_{\max } / \boldsymbol{K}_{\boldsymbol{d}}\left(\mathbf{L ~ g}^{\mathbf{- 1}}\right)\end{array}$ \\
\hline Lactoferrin & $585.1 \pm 34.3$ & $0.52 \pm 0.07$ & 14.4 \\
Lactoperoxidase & $684.5 \pm 122.5$ & $1.31 \pm 0.43$ & 6.8 \\
Lysozyme & $404.0 \pm 35.9$ & $0.51 \pm 0.24$ & 54.8 \\
\hline
\end{tabular}

${ }^{\mathrm{a}} \mathrm{LF}$ and LPO adsorption isotherm data (Figure 2b) were fitted to the Langmuir model (Eqn 1). The lysozyme binding parameters for the pooled batch $(A+B)$ were determined from those obtained for component batches A and B (Table I). 
Table III. Purification table for the recovery of LF from whey in single-cycle HGMF operation.

\begin{tabular}{|c|c|c|c|c|c|c|}
\hline Fraction & $\begin{array}{l}\text { Protein } \\
(\mathrm{mg})\end{array}$ & $\begin{array}{l}\text { LF } \\
(\mathbf{m g})\end{array}$ & $\begin{array}{l}\text { LF/Total } \\
\left(\mathrm{mg} \mathrm{mg}^{-1}\right)\end{array}$ & $\begin{array}{l}\text { Purification } \\
\text { factor }\end{array}$ & $\begin{array}{l}\text { Concentration } \\
\text { factor }\end{array}$ & $\begin{array}{l}\text { Yield } \\
(\%)\end{array}$ \\
\hline Whey & 19927 & 330.5 & 0.02 & 1.0 & 1.0 & 100.0 \\
\hline Flow through & 19105 & 145.6 & 0.01 & 0.5 & 0.4 & 44.1 \\
\hline Wash 1 & 1238 & 15.3 & 0.01 & 0.7 & 0.2 & 4.6 \\
\hline Wash 2 & 365 & 3.1 & 0.01 & 0.5 & 0.0 & 0.9 \\
\hline Wash 3 & 176 & 1.8 & 0.01 & 0.6 & 0.0 & 0.5 \\
\hline Wash 4 & 52 & 1.8 & 0.04 & 2.1 & 0.1 & 0.6 \\
\hline Elution 1 & 140 & 91.8 & 0.66 & 39.5 & 2.8 & 27.8 \\
\hline Elution 2 & 60 & 49.6 & 0.83 & 49.8 & 1.5 & 15.0 \\
\hline Elution 3 & 21 & 20.5 & 0.97 & 58.7 & 0.4 & 6.2 \\
\hline Combined elutions & 221 & 161.8 & 0.73 & 44.2 & 1.4 & 49.0 \\
\hline Mass Balance (\%) & 106.2 & 99.7 & & & & \\
\hline
\end{tabular}


Table IV. Purification table for the recovery of LPO from whey in single-cycle HGMF operation.

\begin{tabular}{lcrcccc}
\hline Fraction & $\begin{array}{l}\text { Protein } \\
(\mathbf{m g})\end{array}$ & \multicolumn{1}{c}{$\begin{array}{l}\text { LPO } \\
(\mathbf{U})\end{array}$} & $\begin{array}{l}\text { LPO/Total } \\
\left(\mathbf{U} \mathbf{~ m g}^{-\mathbf{1}}\right)\end{array}$ & $\begin{array}{l}\text { Purification } \\
\text { factor }\end{array}$ & \multicolumn{2}{c}{ Concentration Yield } \\
factor & $(\%)$ \\
\hline Whey & 19927 & 181780 & 9.12 & 1.0 & 1.0 & 100.0 \\
Flow through & 19105 & 69800 & 3.65 & 0.4 & 0.4 & 38.4 \\
Wash 1 & 1238 & 4770 & 3.85 & 0.4 & 0.1 & 2.6 \\
Wash 2 & 365 & 643.5 & 1.76 & 0.2 & 0.0 & 0.4 \\
Wash 3 & 176 & 261 & 1.48 & 0.2 & 0.0 & 0.1 \\
Wash 4 & 52 & 60 & 1.15 & 0.1 & 0.0 & 0.0 \\
Elution 1 & 140 & 120600 & 861.43 & 94.4 & 6.6 & 66.3 \\
Elution 2 & 60 & 26080 & 434.67 & 47.6 & 1.4 & 14.3 \\
Elution 3 & 21 & 1374 & 65.43 & 7.2 & 0.1 & 0.8 \\
Combined elutions & 221 & 148054 & 669.93 & 73.4 & 2.3 & 81.4 \\
Mass Balance (\%) & 106.2 & 123.0 & & & & \\
\hline
\end{tabular}


Table V. Purification table for the recovery of LF from whey by HGMF multi-cycle processing.

\begin{tabular}{|c|c|c|c|c|c|c|}
\hline Fraction & $\begin{array}{l}\text { Protein } \\
(\mathrm{mg})\end{array}$ & $\begin{array}{l}\text { LF } \\
(\mathbf{m g})\end{array}$ & $\begin{array}{l}\text { LF/Total } \\
\left(\mathrm{mg} \mathrm{mg}^{-1}\right)\end{array}$ & $\begin{array}{l}\text { Purification } \\
\text { factor }\end{array}$ & $\begin{array}{l}\text { Concentration } \\
\text { factor }\end{array}$ & $\begin{array}{l}\text { Yield } \\
(\%)\end{array}$ \\
\hline \multirow[t]{3}{*}{ Cycle 1} & 140 & 92 & 0.66 & 39.5 & 2.8 & 27.8 \\
\hline & 60 & 50 & 0.83 & 49.8 & 1.5 & 15.0 \\
\hline & 21 & 21 & 0.97 & 58.7 & 0.4 & 6.2 \\
\hline Combined & 221 & 162 & 0.73 & 44.2 & 1.4 & 49.0 \\
\hline \multirow[t]{3}{*}{ Cycle 2} & 154 & 73 & 0.48 & 28.5 & 2.2 & 22.1 \\
\hline & 62 & 54 & 0.86 & 51.8 & 1.6 & 16.1 \\
\hline & 16 & 16 & 0.98 & 58.6 & 0.5 & 4.7 \\
\hline Combined & 232 & 142 & 0.61 & 36.8 & 1.4 & 42.9 \\
\hline \multirow{3}{*}{ Cycle 3} & 110 & 74 & 0.68 & 40.6 & 2.2 & 22.4 \\
\hline & 50 & 45 & 0.90 & 54.3 & 1.4 & 13.6 \\
\hline & 12 & 12 & 0.99 & 59.5 & 0.4 & 3.6 \\
\hline Combined & 172 & 132 & 0.76 & 45.9 & 1.3 & 39.6 \\
\hline \multirow[t]{3}{*}{ Cycle 4} & 120 & 81 & 0.68 & 40.5 & 2.4 & 24.4 \\
\hline & 52 & 47 & 0.91 & 54.7 & 1.4 & 14.3 \\
\hline & 12 & 12 & 0.99 & 59.6 & 0.4 & 3.6 \\
\hline Combined & 184 & 140 & 0.76 & 45.8 & 1.4 & 42.3 \\
\hline \multirow[t]{3}{*}{ Cycle 5} & 134 & 90 & 0.67 & 40.1 & 2.7 & 27.0 \\
\hline & 58 & 53 & 0.91 & 54.6 & 1.6 & 15.9 \\
\hline & 14 & 14 & 0.99 & 59.5 & 0.4 & 4.2 \\
\hline Combined & 206 & 156 & 0.76 & 45.5 & 1.6 & 47.1 \\
\hline
\end{tabular}


Table VI. Purification table for the recovery of LPO from whey by HGMF multi-cycle processing.

\begin{tabular}{|c|c|c|c|c|c|c|c|}
\hline \multirow{2}{*}{\multicolumn{2}{|c|}{ Fraction }} & \multirow{3}{*}{$\begin{array}{l}\begin{array}{l}\text { Protein } \\
(\mathrm{mg})\end{array} \\
140\end{array}$} & \multirow{3}{*}{$\begin{array}{l}\text { LPO } \\
\text { (U) } \\
120600\end{array}$} & \multirow{3}{*}{$\begin{array}{l}\text { LPO/Total } \\
\left(\mathbf{U ~ m g}^{-1}\right)\end{array}$} & \multirow{3}{*}{$\begin{array}{l}\text { Purification } \\
\text { factor }\end{array}$} & \multirow{2}{*}{\multicolumn{2}{|c|}{$\begin{array}{l}\text { Concentration } \text { Yield } \\
\text { factor }\end{array}$}} \\
\hline & & & & & & & \\
\hline \multirow[t]{3}{*}{ Cycle 1} & E1 & & & & & 6.6 & 66.3 \\
\hline & $\mathrm{E} 2$ & 60 & 26080 & 434.67 & 47.6 & 1.4 & 14.3 \\
\hline & E3 & 21 & 1374 & 65.43 & 7.2 & 0.1 & 0.8 \\
\hline \multicolumn{2}{|c|}{ Combined } & 221 & 148054 & 669.93 & 73.4 & 2.3 & 81.4 \\
\hline \multirow[t]{3}{*}{ Cycle 2} & E1 & 154 & 110000 & 714.29 & 70.8 & 5.3 & 53.3 \\
\hline & $\mathrm{E} 2$ & 62 & 16800 & 270.97 & 26.9 & 0.8 & 8.1 \\
\hline & E3 & 16 & 1116 & 69.75 & 6.9 & 0.1 & 0.5 \\
\hline \multicolumn{2}{|c|}{ Combined } & 232 & 127916 & 551.36 & 54.7 & 2.1 & 61.9 \\
\hline \multirow[t]{3}{*}{ Cycle 3} & E1 & 110 & 35200 & 320.00 & 32.3 & 1.7 & 17.2 \\
\hline & $\mathrm{E} 2$ & 50 & 5000 & 100.00 & 10.1 & 0.2 & 2.4 \\
\hline & E3 & 12 & 296 & 24.67 & 2.5 & 0.0 & 0.1 \\
\hline \multicolumn{2}{|c|}{ Combined } & 172 & 40496 & 235.44 & 23.8 & 0.7 & 19.8 \\
\hline \multirow[t]{3}{*}{ Cycle 4} & E1 & 120 & 24400 & 203.33 & 19.8 & 1.2 & 11.6 \\
\hline & $\mathrm{E} 2$ & 52 & 2600 & 50.00 & 4.9 & 0.1 & 1.2 \\
\hline & E3 & 12 & 268 & 22.33 & 2.2 & 0.0 & 0.1 \\
\hline \multicolumn{2}{|c|}{ Combined } & 184 & 27268 & 148.20 & 14.5 & 0.4 & 12.9 \\
\hline \multirow[t]{3}{*}{ Cycle 5} & E1 & 134 & 14400 & 107.46 & 10.5 & 0.6 & 6.5 \\
\hline & E2 & 58 & 4820 & 83.10 & 8.1 & 0.2 & 2.2 \\
\hline & E3 & 14 & 346 & 24.71 & 2.4 & 0.0 & 0.2 \\
\hline \multicolumn{2}{|c|}{ Combined } & 206 & 19566 & 94.98 & 9.3 & 0.3 & 8.8 \\
\hline
\end{tabular}




\section{List of Figures}

Figure 1. (a) Annotated photograph; (b) schematic illustration of the automated ProMagic 'rotor-stator' high-gradient magnetic separator rig; (c) CAD drawing of the 'rotor-stator' separator; and (d) photograph of disassembled 'rotor-stator' magnetic filter matrix showing the fixed (larger) and rotatable (smaller) filter disks. Note, the batch adsorption reactor is not shown in Fig.1a, and is represented by 'Feed' in Fig. 1b.

Figure 2. Equilibrium binding isotherms for (a) lysozyme on M-PVA supports fimbriated with pAAc in '25 mg' $(\square)$ and '2.5 g' ( $\square$ - batch 'A'; $\bigcirc$ - batch 'B') scale functionalization reactions (the solid lines through the data represent the fitted Langmuir curves with the parameter values presented in Table I); and (b) LF $(\mathbf{O})$ and LPO $(\triangle)$ on the pooled batch (batches $\mathrm{A}+\mathrm{B}$ ) of pAAc-fimbriated M-PVA supports (the solid lines through the LF and LPO data sets represent the fitted Langmuir curves with the parameter values stated in Table II, and the dashed lines are extensions of the isotherms, based on the same fitted parameters). The Langmuir adsorption isotherm for lysozyme (dotted line without data points) is included for comparison, and was fitted using parameters determined for batches A and B (Table I).

Figure 3. SDS-PAGE analysis of fractions collected during (a) single-cycle HGMF (Cycle 1) and (b) multi-cycle HGMF processing of whey. Panel (a): Whey, flow through and elution 1 samples (lanes 5, 6 and 11 respectively) were all diluted 5-fold before sample preparation. All other samples were prepared without dilution. Lanes: $1-4$, LF standards $(0.25,0.20,0.15$ and $0.10 \mathrm{mg} \mathrm{mL}^{-1}$ respectively); 5, whey feedstock; 6, flow through; 7-10, wash fractions 1-4 respectively; 11-13, elution fractions 1-3 respectively; $14 \& 15$, wash fractions 5 and 6 respectively. Panel (b): Lanes: $1-3, \mathrm{LF}$ standards $\left(0.25,0.15\right.$ and $0.10 \mathrm{mg} \mathrm{mL}^{-1}$ respectively); 
4-6, Cycle 2 elution fractions (E1, E2, and E3 respectively); 7-9, Cycle 3 elution fractions (E1, E2, and E3 respectively); 10-12, cycle 4 elution fractions (E1, E2, and E3 respectively); 13-15, Cycle 5 elution fractions (E1, E2, and E3 respectively). 

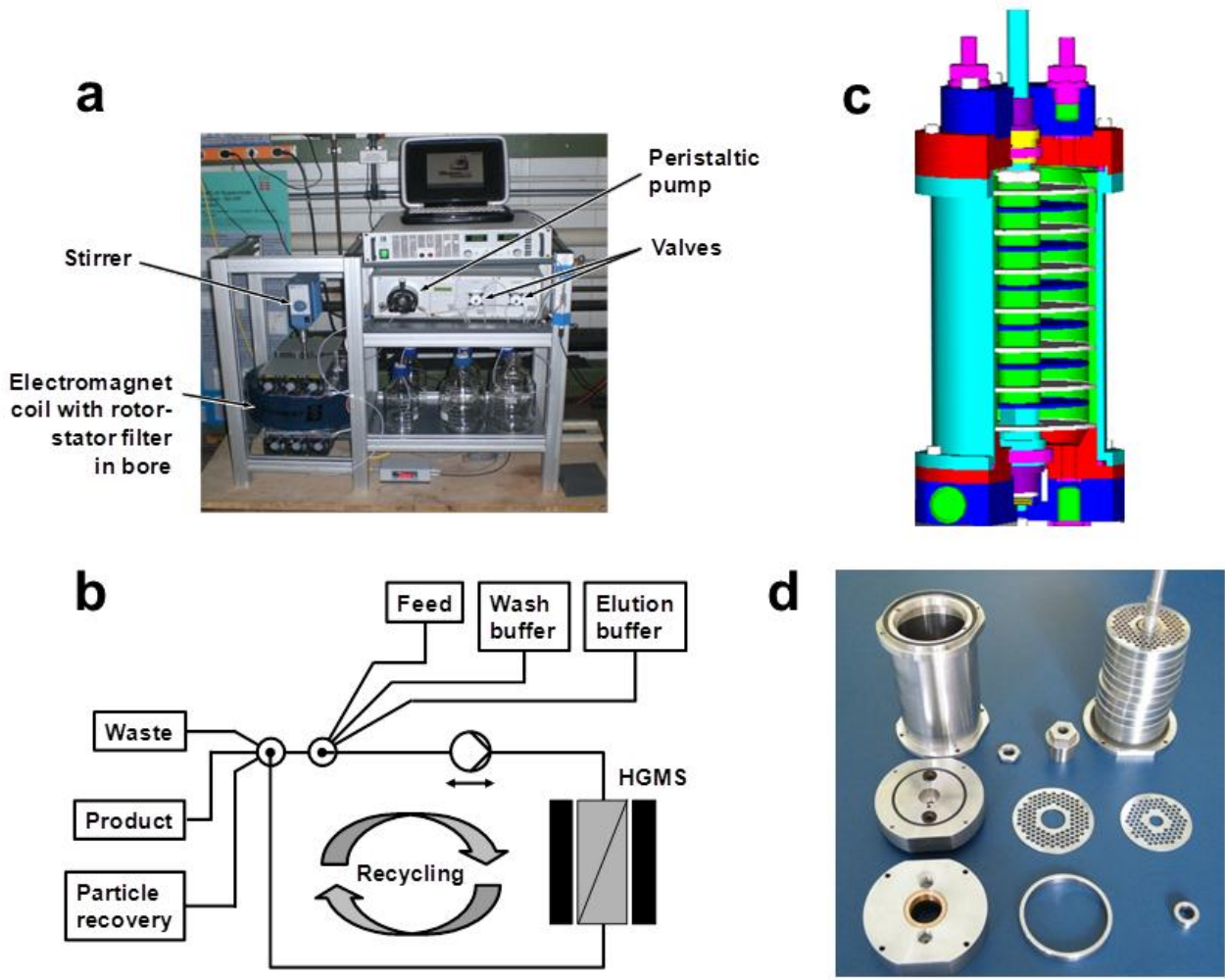

Fig. 1 
a

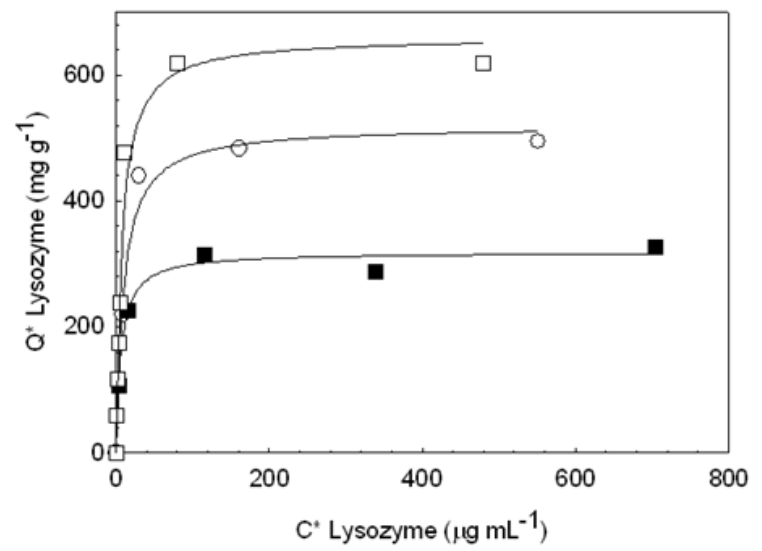

b

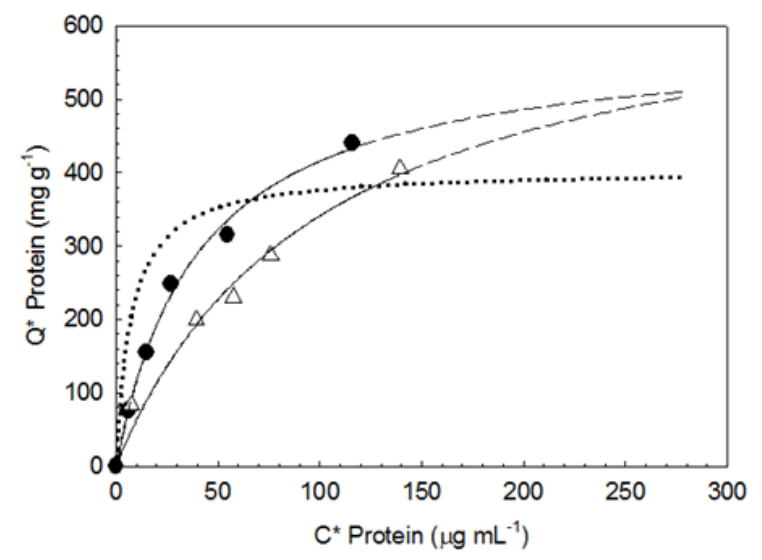

Fig. 2 


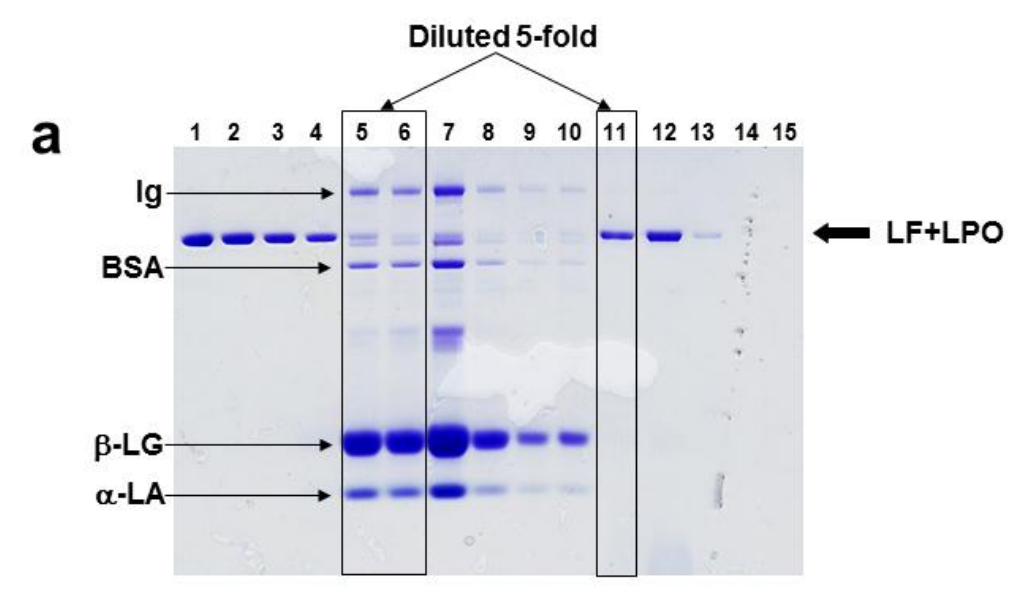

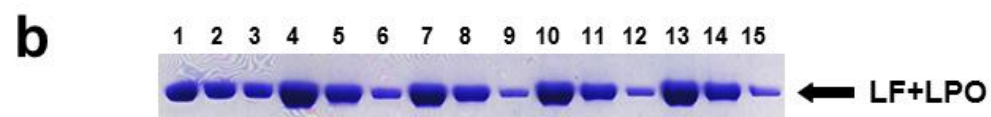

Fig. 3 